\title{
A PARADIPLOMACIA E A GESTÃO DA AMAZÔNIA NO FEDERALISMO BRASILEIRO
}

\author{
Eliana Maria de Souza Franco Teixeira ${ }^{1}$ \\ Universidade Federal do Pará (UFPA)
}

Patrícia Kristiana Blagitz Cichovski²

Centro Universitário Metropolitano da Amazônia (UNIFAMAZ)

\section{RESUMO}

O Brasil passou por uma redefinição de critérios para utilização de recursos do Fundo Amazônia, levando os Estados estrangeiros doadores a bloquear o repasse de recursos para aquele Fundo. Isso gerou uma série de especulações e de embaraços econômicos aos governos estaduais amazônicos, bem como um mal-estar entre os Estados Ocidentais, no que diz respeito ao desenvolvimento sustentável. Com isso, a pesquisa busca responder ao seguinte problema: qual o caminho que os Estados-membros que compõem a Amazônia Legal podem tomar, considerando o federalismo brasileiro, para manter os investimentos e a gestão voltados à mitigação do desmatamento e da degradação ilegais, o desenvolvimento sustentável e a segurança naquelas circunscrições territoriais? Desse modo, o objetivo deste artigo é promover uma releitura do federalismo brasileiro, verificando-se as possibilidades de atuação internacional dos governos estaduais amazônicos para manter os investimentos estrangeiros para fins de preservação, segurança e desenvolvimento sustentável da Amazônia Legal brasileira. A metodologia utilizada foi a hipotético-dedutiva, pois o questionamento tinha como hipótese a resposta que foi ratificada, ou seja, os Estados-membros amazônicos podem praticar a paradiplomacia por meio do Consórcio da Amazônia Legal. Os questionamentos sobre esse resultado serão dissipados quando a Constituição for aprimorada pelo reconhecimento expresso da paradiplomacia.

1 Doutora em Direito pela UFPA. Mestre em Direito Constitucional pela Universidade da Amazônia (UNAMA). Bacharel em Direito pela UNAMA. Professora da Graduação em Direito da UFPA. Professora do Programa de Mestrado em Gestão Pública do Núcleo de Altos Estudos Amazônicos - NAEA/UFPA. ORCID: https://orcid.org/0000-0002-7979-2404 / e-mail: eliana.f.t@hotmail.com

2 Doutora em Direito pela Pontifícia Universidade Católica de São Paulo (PUC-SP). Mestre em Direito pela PUC-SP. Bacharel em Direito pela UFPA. Professora da Graduação em Direito do UNIFAMAZ. ORCID: https://orcid.org/0000-0002-1499-5905 / e-mail: p-blagitz@uol.com.br 
Palavras-chave: consórcio; federalismo; floresta amazônica; meio ambiente; paradiplomacia.

\title{
PARADIPLOMACY AND THE MANAGEMENT OF THE AMAZON IN BRAZILIAN FEDERALISM
}

\begin{abstract}
Brazil went through a redefinition of criteria for the use of resources from the Amazon Fund, leading donor foreign states to block the transfer of resources to that Fund. This generated a series of speculations and economic embarrassments for Amazonian state governments, as well as a malaise among Western states, with regard to sustainable development. Therewith, the research seeks to answer the following problem: what path can the Member States that make up the Legal Amazon take, considering Brazilian federalism, to keep investments and management focused on mitigating illegal deforestation and degradation, the sustainable development and the security in those territorial circumscriptions? Thus, the objective of this article is to promote a reinterpretation of Brazilian federalism, checking the possibilities of international action by Amazonian state governments to maintain foreign investments for the purposes of preservation, security and sustainable development of the Brazilian Legal Amazon. The methodology used was hypothetical-deductive, because the questioning had as hypothesis the answer that was ratified. In other words, the Amazonian member states can practice paradiplomacy through the Legal Amazon Consortium. Questions about this result will be dispelled when the Constitution is improved by the express recognition of paradiplomacy.
\end{abstract}

Keywords: Amazon rainforest; consortium; environment; federalism; paradiplomacy. 


\section{INTRODUÇÃO}

A Constituição brasileira de 1988, influenciada pela Declaração das Nações Unidas de Estocolmo sobre Meio Ambiente de 1972, foi a primeira Constituição brasileira a dedicar capítulo exclusivo à proteção ambiental, embora já houvesse legislação infraconstitucional sobre política nacional do meio ambiente (Lei n. 6.938/81). O meio ambiente foi elevado ao patamar de direito fundamental social, difuso assegurado à coletividade como um todo e norteado pelos princípios do art. 225 da Constituição Republicana de 1988 que conferiram imperatividade aos valores proclamados naquela Declaração.

Durante as três décadas de vigência da Constituição Brasileira de 1988, a legislação ambiental integrativa se solidificou por meio de leis como a Lei de Crimes Ambientais (Lei n. 9.605/98), Lei sobre Política Nacional de Resíduos Sólidos e o Novo Código Florestal. Além disso, no plano internacional, a República brasileira vinha aderindo a compromissos internacionais em prol do meio ambiente.

A Constituição de 1988 deu continuidade no processo histórico constitucional brasileiro à consagração solene do princípio federativo, estampando em seu sistema características tradicionais do Estado Federal, como: a indissolubilidade do pacto federativo, a autonomia dos entes federativos, a repartição de competências e rendas, o poder de auto constituição dos Estados-membros, a representação dos Estados-membros no Poder Legislativo Federal por meio do Senado Federal, além dos mecanismos de controle do Pacto Federativo, como a previsão de intervenção federal e o controle de constitucionalidade.

Apesar de presentes as características indicadas, pouco se avançou na consolidação do princípio de organização política federal, sobretudo em razão das práxis históricas brasileiras no excesso de poderes atribuídos à união federal e da dependência econômica dos Estados-membros quanto às subvenções federais.

O Brasil conta com Constituição e legislações fortes ambientais, um federalismo fraco e uma mudança de paradigma de políticas de preservação ambiental que aflorou internacionalmente, a partir do aumento do desmatamento e da degradação da floresta, bem como com a proposição de novos critérios para utilização dos recursos do Fundo Amazônia. Com isso, esta pesquisa pretende responder ao seguinte questionamento: qual o caminho que os Estados-membros que compõem a Amazônia Legal podem 
tomar, considerando o federalismo brasileiro, para manter os investimentos e a gestão voltados à mitigação do desmatamento e da degradação ilegais, o desenvolvimento sustentável e a segurança naquelas circunscrições territoriais? A hipótese é de que a paradiplomacia possibilita aos Estadosmembros amazônicos transcender às políticas federais, mantendo o compromisso pela preservação da floresta sem prejuízo ao pacto federativo.

Dessa maneira, o objetivo deste artigo é promover uma releitura do federalismo brasileiro, verificando as possibilidades de atuação internacional dos governos estaduais amazônicos para manter os investimentos estrangeiros para fins de preservação, segurança e desenvolvimento sustentável da Amazônia Legal brasileira.

Considerando os estudos de Marconi e Lakatos (2003), o método de investigação adotado será o hipotético-dedutivo, porque parte de um problema ao qual se oferece uma resposta provisória, e, depois, critica-se e verifica-se se a resposta se sustenta, na tentativa de eliminar o erro. Assim, o desenvolvimento da pesquisa partirá da Constituição Republicana de 1988, das decisões internacionais e nacionais sobre a suspensão de investimento estrangeiro no Fundo Amazônia por parte da Alemanha e da Noruega, e depois será afunilada a percepção para as leis e decisões políticas no âmbito do Estado-membro do Pará, em acordo com os demais Estados-membros que compõem a Amazônia Legal brasileira.

O artigo é produto de estudo realizado no âmbito do Projeto de Pesquisa intitulado "Do Consórcio Amazônia Legal: da atuação dos Estados do Pará e do Amapá", aprovado em Edital do Programa Institucional de Bolsas de Iniciação Científica (PIBIC) n. 10/2020, da Universidade Federal do Pará.

\section{DO FEDERALISMO BRASILEIRO NA CONSTITUIÇÃO REPUBLICANA DE 1988}

A forma de Estado Federal foi adotada no Brasil por ocasião da Constituição Republicana de 1891, em que foram rompidas as formas de governo e de Estado, alterando-se a Monarquia para a República e o Estado Unitário para o Estado Federal. Na ocasião, os Estados Unidos da América eram o modelo de federalismo a ser seguido com um elemento concretizador diferenciado, pois, ao passo que o federalismo surgiu naquele Estado 
para tornar a União dos Estados-membros mais firme ${ }^{3}$, aqui a mudança veio para proporcionar mais autonomia às divisões administrativas existentes, mas que não demonstravam consistência administrativa como nos Estados Unidos da América, onde as antigas divisões confederadas detinham soberania e deveriam reduzir seu poder - já aqui a busca era por real autonomia administrativa e política. ${ }^{4}$

$\mathrm{Na}$ raiz histórica de formação do Estado Federal (baseado no federalismo dos Estados Unidos da América), como divisor entre a Confederação e a Federação, encontra-se o compromisso de que os Estados Federados não atuassem no plano internacional, de modo a resguardar o papel do ente central atribuído à União. Tal característica encontrou rígidos contornos naquele contexto histórico como força de manutenção da unidade.

Desde a Constituição de 1891, de fato, o federalismo brasileiro sofreu algumas mudanças jurídicas, considerando-se unidades da federação os Estados-membros e a União, tendo passado por momentos democráticos e autoritários (1937 e 1967)5 até a Constituição Republicana de 1988.

A Constituição brasileira de 1988 restaurou o regime democrático e consagrou o princípio federativo como um de seus pilares, na perspectiva da separação espacial de poder. Incorporou as diversas características

3 Apesar de a finalidade do federalismo ter sido tornar a união dos Estados-membros mais firme, Hamilton, Madison e Jay (2005) destacaram a objeção quanto ao fato de que a federação poderia tornar a União demasiadamente poderosa. Nesse sentido, esse combate à crítica, ressaltando que aquilo que fosse local deveria ser decidido localmente, e que os representantes de cada Estado-membro, além do povo, poderiam atuar para controlar a avidez da União pelo poder. Quer dizer, já havia pelo menos duas constatações: a possibilidade de a União se transformar em um super poder e dos Estadosmembros se manterem empoderados para resolverem problemas locais.

4 Essas conclusões decorrem das leituras de Hamilton, Madison e Jay (2005), combinadas com o Manifesto Republicano de 1870, pois, para os primeiros, a transformação de Confederação para Federação respondia aos problemas da fragilidade da união confederativa. Já o Manifesto Republicano de 1870 marca um período em que não havia propriamente uma federação, mas que fora ventilado o princípio da federação, deixado de lado pelas mudanças na monarquia da época. Assim, registrase, naquele manifesto (BOCAIÚVA et al., 1878, p. 16), a maneira pressionada como as províncias tiveram de se comportar, conforme pode-se perceber: "O Ato Adicional, interpretando a lei de 3 de dezembro, o Conselho de Estado, criando, com o regime de tutela severa, a instância superior e os instrumentos independentes que tendem a cercear ou anular as deliberações dos parlamentos provinciais, apesar de truncados; a dependência administrativa em que foram colocadas as províncias, até para os atos mais triviais; o abuso do efetivo sequestro dos saldos dos orçamentos provinciais para as despesas e para as obras peculiares do município neutro; a restrição imposta ao desenvolvimento dos legítimos interesses das províncias pela uniformidade obrigada, que forma o tipo da nossa absurda administração centralizadora, tudo está demonstrando que posição precária ocupa o interesse propriamente confrontado com o interesse monárquico que é, de si mesmo, a origem e a força da centralização." Quer dizer, no processo de descentralização houve, em parte do período monárquico, a influência do princípio da federação, mas não se manteve até a Constituição de 1891. Com isso, a Constituição Republicana de 1891 teve o atributo de estabelecer o tipo de estado federal para promover a descentralização efetiva das províncias (Estados-membros).

5 Sobre o período constitucional da Ditadura (1964 a 1985), recomenda-se a leitura de Tavares (2013, p. 99-108). 
tradicionalmente apontadas pela doutrina como elementos essenciais do Estado Federal.

Até a chegada da Constituição de 1988, os Municípios não eram considerados entes federados, quando ocorreu o processo de municipalização e consequente alocação de poderes federativos aos Municípios que sofrem críticas, como é o caso da manifestação de Silva (2009), que não aceita a qualificação concedida pela Constituição brasileira de 1988, pois os Municípios continuaram a pertencer a algum Estado 6 .

As competências administrativas e legislativas estão descritas na Constituição Brasileira de 1988, sendo as competências administrativas e legislativas da União determinadas nos arts. 21 e 22. Já as competências dos Municípios estão previstas no art. 30 e as competências dos Estados-membros diminutas, correspondentes ao art. 25, podendo também decorrer de delegação da União de acordo com o 22, e as competências comuns da União, dos Estados-membros e dos Municípios nos arts. 23 e 24. Com isso, a União e os Municípios detêm a maior parte das competências constitucionais, deixando para os Estados-membros a atuação legislativa ${ }^{7}$ precipuamente voltadas para questões ambientais e tributárias, sendo as demais competências legislativas direcionadas à União. No campo administrativo, verifica-se de maneira mais evidente a atuação dos Estados-membros, mas, ainda assim, tal atuação fica em segundo plano se colocada lado a lado com os Municípios, que tratam dos interessas locais. ${ }^{8}$

6 Silva (2009, p. 474-475) analisa a inclusão dos Municípios como entes da federação a partir da Constituição de 1988, observando que esse entendimento é contrário à realidade, pois " [...] essa é uma tese equivocada, parte de premissas que não podem levar à conclusão pretendida. Não é porque uma entidade territorial tenha autonomia político-constitucional que necessariamente integre o conceito de entidade federativa. Nem o Município é essencial ao conceito de federação brasileira. Não existe federação de Municípios. Existe federação de Estados. Estes é que são essenciais ao conceito de qualquer federação [...] Não é uma união de Municípios que forma a federação [...] Outro aspecto que mostra que os Municípios continuam a ser divisões dos Estados acha-se no fato de que sua criação, incorporação, fusão e desmembramento far-se-ão por lei estadual, dentro do período determinado por lei complementar federal (art. 18, $\S 4^{\circ}$, redação da EC-15/96), e dependerão de plebiscito (que é sempre consulta prévia) das populações diretamente interessadas."

7 Em consulta ao site da Assembleia Legislativa do Estado do Pará, é possível perceber que, de 1988 até 2018, a "grande movimentação legislativa" está concentrada nas áreas ambientais e tributárias, além de dimensionar a organização administrativa daquele Estado. BRASIL. Assembleia Legislativa do Estado do Pará. Disponível em: https://www.alepa.pa.gov.br/bancodeleis.asp. Acesso em: 14 nov. 2019.

8 As competências no aspecto ambiental comuns e concorrentes estão previstas no art. 23, VI e VII, e no art. 24, VI e VIII, conforme pode-se observar:

“Art. 23. É competência comum da União, dos Estados, do Distrito Federal e dos Municípios:

VI - proteger o meio ambiente e combater a poluição em qualquer de suas formas;

VII - preservar as florestas, a fauna e a flora;

Art. 24. Compete à União, aos Estados e ao Distrito Federal legislar concorrentemente sobre:

VI - florestas, caça, pesca, fauna, conservação da natureza, defesa do solo e dos recursos naturais, 
Para Silva e Carvalho (2018), a continuidade constitucional da forma federal de Estado pela Constituição Republicana de 1988 não significou o fortalecimento da federação, pois o federalismo seria fraco por ser concentrado na União, "[...] o que por outro lado impossibilita os Estados de terem participação maior na tomada de decisões" (SILVA; CARVALHO, 2018, p. 1501).

Após três décadas da Constituição da República Federativa do Brasil de 1988, a gestão ambiental em nível federal fez que os Estados-membros que compõem a Amazônia Legal reacendessem as possibilidades de atuação administrativa e legal, pois se perceberam como entes da Federação que podem posicionar-se nacional e internacionalmente para protegerem a região amazônica.

Os Estado-membros podem e devem se organizar para atuar em conjunto, de modo coordenado, e aproveitando a criação legislativa pensada no final da década de 90, mas que se apresentou como regra em meados do novo milênio. Trata-se dos chamados consórcios, em que os entes da federação podem se unir, formar uma pessoa jurídica e atuar em conjunto em prol de um objetivo. Assim, podem realizar políticas legislativas, públicas e administrativas, a fim de fortalecer determinada área comum, além de poderem realizar convênios internacionais com bancos e organizações internacionais que pretendam auxiliar e/ou investir no Brasil. Enfim, os Estados-membros existem e podem atuar de maneira efetiva e em prol de seus desenvolvimentos, como será verificado na seção 4.

O Estado, na perspectiva da União, em visão isolada, passou a não conseguir resolver todos os problemas, possibilitando a atuação de outros entes da federação na solução de questões emergentes e nas relações internacionais.

A atuação organizada e consorciada de Estado-membros e de Municípios poderia levar ao questionamento de se tal atuação feriria o princípio da lealdade federal. Zago (2016, p. 510), tratando acerca do princípio da lealdade federal, demonstra que pode ser identificado como "[...] a restrição ao exercício de um direito por um ente federativo, em consideração aos interesses de outros entes federativos, os quais poderiam ser sensivelmente prejudicados por essa atuação." No campo da atuação legislativa, a autora indica a cooperação federal como meio de resolver conflitos e cumprir com o princípio da lealdade federal. Cumpre destacar que tal princípio não se proteção do meio ambiente e controle da poluição;

VIII - responsabilidade por dano ao meio ambiente, ao consumidor, a bens e direitos de valor artístico, estético, histórico e paisagístico.” 
apresenta expressamente na Constituição Republicana de 1988. Todavia, o Supremo Tribunal Federal já decidiu sobre questões relativas ao federalismo, considerando o princípio da lealdade federal. Para tanto, observa-se que já houve apreciação de referido princípio da lealdade federal em sede de ADI/ MC 2377, ADI 2452 e RE 572262. ${ }^{9}$ Esclarecido o significado de princípio da lealdade federal, pode-se inferir que a criação de consórcios não ocorreu no Brasil desde o início da promulgação da Constituição de 1988, mas foi incluída por Emenda Constitucional (EC), sendo posteriormente regulada por lei (pela Emenda Constitucional n. 19/1998 e pela Lei n. 11.107/2005). Com isso, admitindo-se sua constitucionalidade, não há que tratar do tema como ato inconstitucional. Por isso, esse questionamento pode ser respondido no sentido de que a atuação de entes da Federação em consórcio não fere o princípio da lealdade federal.

\section{DO CRESCIMENTO DO DESMATAMENTO E DA DEGRADAÇÃO NA AMAZÔNIA}

De acordo com o Relatório de Atividades 2018 do Fundo Amazônia (BRASIL, 2019a, p. 8),

Até o final de 2018, o referido fundo recebeu aproximadamente R $\$ 3,4$ bilhões em doações, sendo $93,8 \%$ provenientes do governo da Noruega, 5,7\% do governo da Alemanha, por meio do KfW Entwicklungsbank, e 0,5\% da Petróleo Brasileiro S.

A. (Petrobras).

De acordo com dados do Instituto Nacional de Pesquisas Espaciais (INPE), o desmatamento no Estado-membro do Pará aumentou de 2017 a 2018, sendo que em 2017 foram desmatados $2433 \mathrm{~km}^{2}$ e, em 2018, o desmatamento cresceu para $2744 \mathrm{~km}^{2}$. O Relatório de Atividades de 2018 do Fundo da Amazônia constatou que houve um aumento de $14 \%$ de desmatamento da floresta amazônica. Os dados revelados pelo INPE, os quais mostraram o aumento de desmatamento da floresta amazônica, levaram a uma crise internacional em termos de parceiros doadores para o Fundo Amazônia, tendo Alemanha e Noruega suspendido, até o momento, as doações para aquele fundo.

Enfim, a constatação científica de aumento do desmatamento na Amazônia e as ideias divulgadas pelo Ministério do Meio Ambiente, acerca

9 O princípio da lealdade federal tem origem alemã, como princípio não escrito, mas que deve ser observado nas relações entre a União e os Estados, sendo no Brasil denominado como o "princípio da conduta federativa amistosa". Sobre o assunto, sugere-se, além da leitura de Zago (2016), a leitura de Leoncy (2014). 
dos novos critérios para o uso dos recursos, provocaram a suspensão das doações por parte da Noruega e da Alemanha ao Fundo Amazônia. Assim, ficou em evidência o questionamento sobre a condução da política ambiental pelo soberano Estado brasileiro. Daí surge o questionamento quanto ao exercício de soberania do Brasil.

Abdenur e Muggah (2019) argumentam que a soberania de um Estado deve ter como pressuposto a proteção de bens públicos de modo responsável. Discorrem sobre os mecanismos internacionais que são utilizados para a proteção das florestas, utilizando como exemplos o Acordo de Paris e o Protocolo de Kyoto, além da possibilidade de estabelecimento de recompensas pela redução em emissões de gás de efeito estufa.

O momento político criou a oportunidade de fortalecimento da sociedade civil, dos Estados e dos Municípios brasileiros, tendo vários governadores se organizado para, de maneira coordenada, preservarem a Amazônia, inclusive com a proposição à União de descentralização dos valores do Fundo Amazônia (ABDENUR; MUGGAH, 2019).

Para o Instituto do Homem e Meio Ambiente da Amazônia, há diferença entre desmatamento e degradação. Desmatamento significa "o processo de realização do corte raso, que é a remoção completa da vegetação florestal", e a degradação "é caracterizada pela extração das árvores, normalmente para fins de comercialização da madeira, exemplos de degradação são os incêndios florestais [...]" (IMAZON, 2019).

De acordo com dados do Imazon (2019), “[...] a destruição da floresta, por queimadas ou retirada de madeira, teve um crescimento de $394 \%$ em comparação com o mês de outubro do ano passado." Quanto ao desmatamento na Amazônia, houve um aumento de $212 \%$, em comparação ao ano passado. "No ranking do desmatamento por estado, o Pará lidera com 59\%. Em seguida, aparecem: Mato Grosso (14\%), Rondônia (10\%), Amazonas (85\%), Acre (6\%), Roraima (2\%) e Amapá (1\%)".

Em análise mais acurada acerca das áreas de desmatamento na Amazônia, o Imazon (2019) observou que 54\% do desmatamento ocorreram em áreas privadas ou sob diversos estágios de posse, sendo que o restante de $32 \%$ foi registrado em áreas de assentamentos, $7 \%$ em Unidades de Conservação e 7\% em Terras Indígenas.

O Imazon (2019) destaca que

A APA Triunfo do Xingu, no Pará, a Florex Rio Preto-Jacundá, em Rondônia, e a Resex Guariba-Roosevelt, Mato Grosso, foram as Unidades de Conservação mais desmatadas na Amazônia. Das dez terras indígenas mais desmatadas, oito ficam no 
Estado do Pará. No topo da lista, estão a TI Cachoeira Seca do Iriri, TI Ituna/Itatá e a TU Apyterewa.

Corroborando o avanço do desmatamento na Amazônia Legal, observa-se também o gráfico que trata do tema na região da Amazônia Legal no período de 1988 a 2019, de acordo com o Portal do Governo Brasileiro, Educa Clima do Ministério do Meio Ambiente.

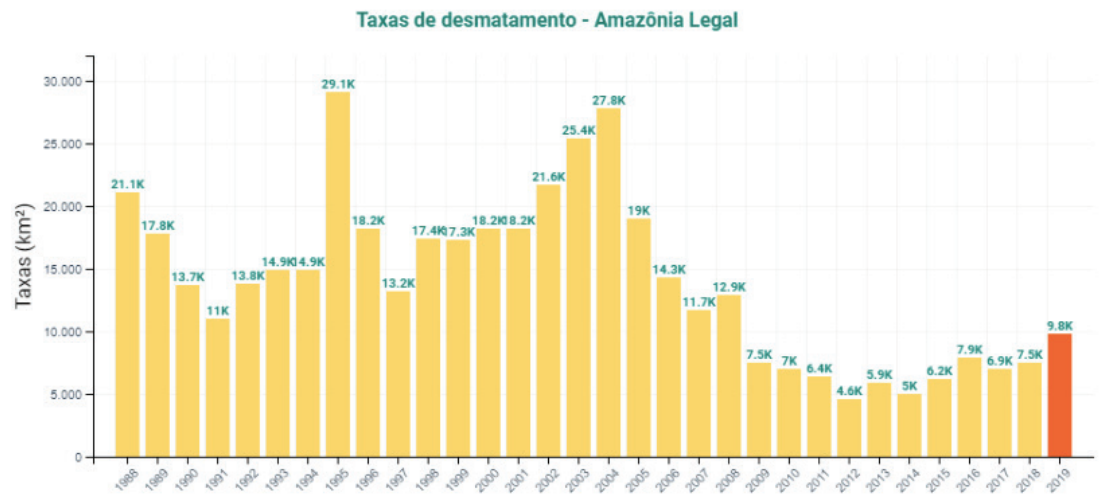

Gráfico 1 - Trajetória do desmatamento na Amazônia Legal.

Fonte: Brasil (2020).

Em pouco mais de três décadas, observa-se oscilações no tocante ao desmatamento da Amazônia Legal, com grandes picos nos anos de 1995, 2003 e 2004, e níveis mais baixos verificados no período de 2010 a 2018. O ano de 2019 aponta a elevação do nível de desmatamento que pode desenhar curva ascendente derivada das políticas estabelecidas para o tema.

$\mathrm{O}$ aumento do desmatamento e da degradação ambiental foram objeto de debate nacional e internacional e levaram ao congelamento de repasses de recursos para o Fundo Amazônia.

\section{DA SUSPENSÃO DE REPASSES DE RECURSOS FINANCEIROS INTERNACIONAIS PARA O FUNDO AMAZÔNIA}

De acordo com o Fundo Amazônia, esse fundo foi criado pelo Decreto n. 6.527, de 1 de agosto de 2008, "com a finalidade de captar recursos para investimentos não reembolsáveis em ações de prevenção, monitoramento e combate ao desmatamento, e de promoção da conservação e do uso 
sustentável da Amazônia Legal” (BRASIL, 2019a).

Para Marcovich e Pinsky (2014, p. 280)

O Fundo Amazônia, criado pelo Governo Federal em 2008, é gerido pelo Banco Nacional de Desenvolvimento Econômico e Social (BNDES). Trata-se de uma iniciativa pioneira de captação e gestão de recursos de doações voluntárias para reduzir o desmatamento e promover o desenvolvimento sustentável a 30 milhões de habitantes do bioma amazônico. O Fundo Amazônia já recebeu doações no valor de R \$ 1,7 bilhão (cerca de USD 787 milhões).

Ainda de acordo com Marcovich e Pinsky (2014), a Política Nacional de Meio Ambiente é concentrada nas mãos do Estado que não consegue exercer efetivamente o comando e o controle sobre as terras da Amazônia, sendo registrados altos índices de desmatamento, agropecuária extensiva, baixo desenvolvimento humano e caótica distribuição de terras. A verificação de dados do Instituto Nacional de Pesquisas Espaciais (INPE), comparativos de 2012 a 2013, já revelavam o aumento de $27,83 \%$ de desmatamento na Amazônia.

Naquele momento, já havia uma atenção científica por parte de Marcovich e Pinsky (2014) para o fato, sendo que aquele cenário de aumento do desmatamento exigia uma mudança de logística, com estímulo à educação ambiental voltada à sustentabilidade e à inovação ambiental, bem como de incentivos e apoio àqueles responsáveis pela preservação da floresta.

Portanto, em 2013, a partir de dados coletados pelo INPE e pela pesquisa realizada por Marcovich e Pinsky (2014), observa-se que o aumento do desmatamento não é uma constatação tão recente e que já deveria estar na agenda governamental uma política para lidar com a questão. Além do desmatamento, a questão das doações financeiras, segundo os referidos autores, demonstrou que o governo norueguês representou $96,7 \%$ das doações, seguidos da Alemanha com 2,8\%, e da Petrobrás com $0,5 \%$.

Os estudos de Marcovich e Pinsky (2014) encerram ressaltando a importância do Fundo Amazônia, de sua inovação como fundo para proteger a floresta e que poderia ser um tipo de Fundo a ser replicado para proteção de outras florestas. Ocorre que, apesar de o lema do Fundo Amazônia ser "O Brasil cuida. O mundo apoia. Todos ganham"10, a bandeira do Fundo no quesito apoio do mundo sofreu modificações recentes com a suspensão de repasses de recursos financeiros da Noruega e da Alemanha, em um curto espaço de tempo (2013-2019), em virtude do aumento das queimadas na

10 As informações governamentais disponíveis sobre o Fundo Amazônia podem ser encontrados no site http://www.fundoamazonia.gov.br/pt/fundo-amazonia/. 
Amazônia e da posição do atual governo com relação ao que compõe o discurso do desenvolvimento sustentável e às declarações não esclarecedoras acerca de suas proposições para a manutenção da floresta amazônica. Os discursos acalorados e as trocas de farpas políticas nacionais e internacionais ameaçam de extinção a proposta de inovação ambiental provocada pela concepção do Fundo Amazônia.

Borges (2019) informou que o atual governo preparou mudanças para a utilização dos recursos que a Noruega e a Alemanha investiriam para bancar os projetos do Fundo Amazônia. Por meio de decreto, as normas do Fundo permitiriam a utilização dos recursos para pagar indenizações a donos de propriedades privadas que vivam em áreas de conservação. $\mathrm{O}$ interesse do governo era eliminar passivos de indenizações que não foram pagos desde a criação das unidades de conservação.

Com isso, o Brasil deixou de receber as doações da Noruega e da Alemanha, causando a redução de recursos para a preservação da floresta amazônica e para promover uma educação ambiental sustentável a partir daquele Fundo.

Apesar da importância do Fundo Amazônia observada por Marcovich e Pinsky (2014), a verificação de um estudo mais recente questiona a importância do Fundo, no sentido de mostrar que os valores doados não conseguem fazer frente às reais necessidades de valor de mercado para a manutenção das florestas. Assim, Santos (2018), citando Manoel Sobral Filho, diretor do Fórum sobre Florestas da Organização das Nações Unidas (ONU), enfatiza que o valor de mercado de florestas tropicais é baixo, sendo necessário aumentar o valor das florestas para a comunidade internacional, pois o valor necessário para a real conservação da floresta amazônica seria de 20 bilhões de dólares anuais.

Os valores doados ao Fundo Amazônia pelos governos da Noruega, Alemanha e pela Petrobrás totalizaram, no período de 2009 a 2018, o montante de R \$ 3.396.694.793,53. Se for considerada a conversão para o dólar estadunidense, o valor é U\$ 1.288.235.378,26. É importante observar que a Noruega realizou doações no período de 2009 a 2018, na importância de $\mathrm{R} \$ 3.186 .719 .318,40$. A Alemanha, por sua vez, realizou doações nos anos de 2010, 2013, 2014 e 2017, perfazendo um total de R\$131.992.896,00. A Petrobrás S/A foi bem mais modesta nas doações ocorridas no período de 2011 a 2018, totalizando o valor de R\$ 17.285.079,13 (BRASIL, 2019a).

Ao se verificar individualmente cada doação por ano, observando-se somente as doações da Noruega no Relatório de Doações recebidas pelo 
Fundo Amazônia, é possível constatar que nenhuma das doações isoladamente chega à casa do bilhão. Logo, os valores doados não seriam suficientes para manter a segurança da floresta em termos de desenvolvimento sustentável, sem desmatamento puro e simples (muitas das vezes, criminoso), conforme a posição já salientada pelo Diretor do Fórum sobre Floretas da ONU.

Sem avançar acerca da importância do Fundo Amazônia, pontua-se que este recebeu doações durante expressivo período, sendo tais valores geridos pelo BNDES, o qual vinculava os recursos para os Projetos e tinha dois Comitês (Comitê Orientador e Comitê Técnico) que, por sua vez, atuavam no combate ao desmatamento. É importante destacar que, junto com o discurso governamental de que os recursos não seriam suficientes, também veio a extinção daqueles Comitês (Decreto n. 9.759, de 11 de abril de 2019), passando a administração a ser mais centralizada no tocante às políticas voltadas para a floresta, apesar de constar no site do Fundo Amazônia que "até a presente data, não foi definida a nova governança do Fundo Amazônia."

Longe de se tentar estabelecer qual é a posição certa, quer dizer, se os valores doados são suficientes para combater o desmatamento e promover o desenvolvimento sustentável, o que se constata é que os recursos deixaram, naquele momento, de serem doados, tanto pela Noruega quanto pela Alemanha, em virtude da posição governamental sobre o assunto.

Conforme noticiado por Senra (2019), o Ministério do Meio Ambiente da Alemanha congelou as doações de 35 milhões de euros para o Fundo Amazônia, em consequência da revisão de critérios adotados para governança e aplicação dos recursos doados pelo governo atual. Não bastasse o congelamento das doações, o governo alemão também divulgou a dúvida acerca do apoio alemão ao acordo de livre comércio entre Mercosul e União Europeia.

Passarinho e Senra (2019) destacam que as doações de valores do Canadá, Reino Unido e do G7 não conseguem fazer frente às perdas dos valores doadores pela Noruega e Alemanha. De acordo com os autores, o Fundo Amazônia deixou de receber R\$ 299 milhões para o ano de 2019.

Em 3 de outubro de 2019, Schelp (BRASIL, 2019b) noticiou que a Alemanha confirmava que 33 milhões de euros seriam doados para o Fundo Amazônia, faltando a Noruega confirmar, à época, se também manteria a doação de recursos ao Fundo. Importante destacar, ainda, que a Alemanha confirmou a doação, mas também ressaltou que esperaria as tratativas 
entre o governo brasileiro e o norueguês sobre a questão para fazer a referida doação, o que não ocorreu até o final daquele ano.

\section{DO CONSÓRCIO DOS ESTADOS DA AMAZÔNIA LEGAL}

A partir da Reforma da Administração Pública, mais particularmente da gestão pública, ou seja, do modo de gerir a Administração Pública, estabelecida pela Emenda Constitucional n. 19/1998, considerando-se seu processo de discussão em meados de 1996, não há como deixar de observar os escritos de Bresser-Pereira (2009), bem como de verificar o desenvolvimento posterior daquela Reforma, além das dificuldades em se efetivar a descentralização federal.

Ao examinar as explicações de Bresser-Pereira (2009), observa-se o cuidado em tratar de descentralização e de delegação de poderes, inclusive sendo citado o caso dos Estados Unidos da América, em que as subunidades (Estados-membros) abriram mão de suas soberanias para centralizar mais o poder vivido pela forma de Estado Confederal. Para Bresser-Pereira (2009, p. 299),

[...] a descentralização é uma estratégia de gestão pública, enquanto a delegação de poderes é uma decisão com consequências gerenciais. A descentralização é em geral decidida de cima para baixo, sendo uma estratégia para aumentar a capacidade dos escritórios centrais de atingir os objetivos propostos, enquanto a delegação é geralmente uma reposta a demandas por maior autonomia local e regional, com a qual os funcionários governamentais do governo central concordam com relutância. A delegação é o produto de negociações políticas em torno da divisão de poderes entre os níveis de governo.

A Constituição Republicana de 1988 já definiu, como mencionado, as competências administrativas e legislativas de cada ente da federação. Assim, a descentralização se ampliou com a Reforma Administrativa (EC n. 19/1998) e a "delegação" - não exatamente conforme a definição de Bresser-Pereira (2009), já ocorreu por via constitucional ${ }^{11}$, mas o afunilamento concreto, na perspectiva desta pesquisa - aconteceu legalmente somente em 2005, a partir da promulgação da Lei n. 11.107, de 6 de abril, sendo disposta de normas gerais para contratação de consórcios públicos. ${ }^{12}$

11 Observa-se a inclusão dos consórcios públicos a partir da EC n. 19/98: "Art. 241. A União, os Estados, o Distrito Federal e os Municípios disciplinarão por meio de lei os consórcios públicos e os convênios, bem como a transferência total ou parcial de encargos, serviços, pessoal e bens essenciais à continuidade dos serviços transferidos" (BRASIL, 1998b).

12 Assim dispõe a Lei n. 11.107/2005 em seu art. $1^{\circ}$, essa Lei dispõe sobre "normas gerais para a União, os Estados, o Distrito Federal e os Municípios contratarem consórcios públicos para a realização de objetivos de interesse comum e dá outras providências" (BRASIL, 2005a). 
Seguindo a linha da descentralização e exercendo-se as competências administrativas e legislativas constitucionais, além da "delegação" permitida pela EC n. 19/1998, os Estados da Amazônia Legal (Acre, Amapá, Amazonas, Maranhão, Mato Grosso, Pará, Rondônia, Roraima e Tocantins) celebraram um consórcio para a proteção e o desenvolvimento da Amazônia Legal em 2017, conforme consta no Diário Oficial do Estado do Pará, Ano CXXVII da IOE $128^{\circ}$ da República n. 33.513.

Em 2017, os Estados-membros da Amazônia Legal, já mencionados, celebraram o Protocolo de Intenções do Consórcio Interestadual de Desenvolvimento Sustentável da Amazônia Legal. Esse protocolo de intenções foi ratificado pelo Estado-membro do Pará, pela Lei Estadual n. 8. 573, de 6 de dezembro de 2017.

A cláusula $7^{\text {a }}$ do Consórcio Interestadual de Desenvolvimento Sustentável da Amazônia Legal ${ }^{13}$ estabeleceu as finalidades do Consórcio, sendo destacadas:

\footnotetext{
I - o desenvolvimento econômico e social da Amazônia Legal, de maneira harmônica e sustentável;

II - a integração e o fortalecimento regionais e do seu papel político e econômico, no contexto nacional e internacional;

$[\ldots]$

$\mathrm{V}$ - o desenvolvimento de projetos de infraestrutura e logística com vistas à integração da região e inserção nacional e internacional;

$[\ldots]$

VIII - a atuação na captação de investimentos e ampliação das fontes de recursos voltadas ao fomento e desenvolvimento da Amazônia e conservação de sua biodiversidade, florestas e clima;

IX - o desenvolvimento de projetos voltados a uma economia de baixo carbono (AMAZONAS, 2017, grifo nosso).
}

As finalidades enfatizadas sobre o Consórcio da Amazônia Legal contemplam a possibilidade de contato internacional para a promoção de desenvolvimento econômico e social daquela região, a partir do desdobramento de projetos de infraestrutura e logística, da captação de recursos voltados para a conservação de sua biodiversidade, da floresta e do clima, além de projetos voltados para uma economia de baixo carbono. Com isso, constata-se que a posição da União na representação da República Federativa do Brasil em alterar os critérios de utilização dos recursos doados por outros Estados (Noruega e Alemanha) criou um

13 Para simplificar a citação da nomenclatura do Consórcio Interestadual de Desenvolvimento Sustentável da Amazônia Legal, a pesquisa adotará a nomenclatura Consórcio da Amazônia Legal. 
obstáculo para a conservação das florestas da Amazônia. Por outro lado, ao mesmo tempo, possibilitou o contato internacional, por meio do Consórcio da Amazônia Legal, para o desenvolvimento de projetos responsáveis de proteção, preservação e desenvolvimento no âmbito da Amazônia Legal. Assim, promove-se a descentralização real e regional (para além da compreensão de regiões geográficas, mas referindo-se à região da Amazônia Legal brasileira) da administração e a busca de recursos para aqueles Estados-membros, considerando questões locais e regionais, em prol do desenvolvimento sustentável.

É necessário fortalecer a união dos Estados-membros da Amazônia Legal, a fim de ser evitado alguns comportamentos já verificados em consórcios públicos municipais, em que se constatou a atuação desleal entre os consorciados que, individualmente, começaram a atuar com olhares voltados somente para as suas necessidades individuais. ${ }^{14}$

Esse modelo de cooperação federativa é potencialmente adequado ao plano ambiental, pois a lógica do meio ambiente é refratária a atuações isoladas ou estanques e incompatível com rígidos esquemas de repartição de competências, exigindo atuação em todos os níveis da federação.

Por outro lado, a Amazônia é constitucionalmente definida como "patrimônio nacional", art. $225, \S 4^{\circ}$, da CRFB/88, o que implica dois significados: o direito de o Estado brasileiro estabelecer sua própria política ambiental e de desenvolvimento (soberania em matéria ambiental) e o dever de obediência aos patamares mínimos de proteção ambiental da legislação federal pelos Estados e Municípios. O dispositivo não torna exclusivamente federal a política ambiental nas áreas de relevante interesse ecológico como a Amazônia, permitindo aos Estados-membros políticas mais protetivas do meio ambiente.

Nesse sentido, a gestão da Amazônia Legal, em termos ambientais, figurará de maneira regional e mais interessada nos problemas que circundam a região, tais como a segurança quanto à prevenção ao desmatamento, a degradação e o desenvolvimento sustentável. A gestão da Amazônia Legal perpassará para além dos entes individualmente considerados, quer dizer pela União e pelos Estados-membros, conformando-se à gestão de Estados-membros em que a Amazônia está presente, tornando o processo de gestão mais forte e fundado na resolução de anseios mais localizados e regionais.

14 Sobre o assunto, sugere-se a leitura de MACHADO, José Ângelo; ANDRADE, Marta, Leone Costa (2014), que expressam a atuação de consorciados públicos de maneira desleal, atuando como "free rider", em que o consorciado verifica que pode se beneficiar sem cooperar. Este se comportaria como free rider, ou seja, agiria individualmente em detrimento da proposta de fortalecimento coletivo previsto pelos consórcios. 


\section{PARADIPLOMACIA, FEDERALISMO E O CONSÓRCIO AMAZÔNICO}

O tema da Paradiplomacia exige reflexões acerca do federalismo, posto que esse caminho pode ser tomado em virtude de desvios relacionais entre os entes da federação. Nesse sentido, os estudos de Wright (1974) acerca do federalismo estadunidense trazem alguma luz para a verificação das relações intergovernamentais entre os atores da federação. De acordo com Wright (1974), existiram cinco fases das relações intergovernamentais: (1) conflitiva; (2) cooperativa; (3) concentrada; (4) criativa; e (5) competitiva. Em tais fases, verificou-se, respectivamente, de modo exemplificativo: os conflitos iniciais entre Estados-membros; a necessidade de cooperação diante da depressão e das guerras; a concentração em questões próprias de desenvolvimento como a renovação urbana, tratamentos de lixo, construção de bibliotecas e outros; recursos para desenvolvimento de projetos, com mais de 40 (quarenta) projetos desenvolvidos; e a competitividade estabelecida para o desempenho administrativo e a efetiva entrega de bens e serviços públicos. Tais fases descrevem o federalismo estadunidense e o importante é demonstrar que existem fases intergovernamentais entre os entes da federação que podem alterar suas relações internas e internacionais.

As relações intergovernamentais, segundo Anderson (1960 apud WRIGHT, 1974, p. 2), servem "para designar um importante corpo de atividade ou interações ocorrendo entre unidades governamentais de todos os tipos e níveis dentro do [Estados Unidos] sistema federal"15. E é a partir dessa definição geral que Wright (1974) parte para construir a sua concepção de relações intergovernamentais. O contexto de análise das relações intergovernamentais foram os Estados Unidos da América, mas pode ser adotado para outros Estados Federais, sempre se observando as peculiaridades de cada um.

O propósito deste estudo não é classificar o federalismo brasileiro desde a sua origem, mas de verificar sua caracterização atual. Neste sentido, o federalismo brasileiro passa a ser repensado com o novo governo, pois os acontecimentos nacionais acerca do aumento do desmatamento e da degradação na Amazônia fizeram que as relações intergovernamentais dos Estados-membros daquela região fossem fortalecidas, tendo estes percebido 
que, na qualidade de entes autônomos e que compõem uma regionalização, podem estabelecer contatos internacionais para fins da realização de interesses locais e regionais, especialmente os de caráter ambiental.

Apesar da crise mundial da democracia, a paradiplomacia aparece como uma via de solução para os Estados-membros.

No contexto dos Estados Federais do século XXI e das influências do mundo globalizado, a atuação dos entes federados deve ser redimensionada, a partir das necessidades daqueles entes, para resolver questões locais, nas quais a União não exerça o papel catalizador e solucionador dos problemas das unidades federativas. A expressa afirmação de que os Estados Federados não podem agir ut singuli na ordem internacional deve ser específica na Constituição do Estado. ${ }^{16}$

Além disso, conforme Garcia-Pelayo (1984), o federalismo, como síntese dialética de duas tendências contraditórias - tendência à unidade e tendência à diversidade -, não pode subsistir apenas em perspectiva ou força centralizante. A atuação dos Estados é indispensável para assegurar o equilíbrio do ideal federativo.

O termo paradiplomacia, neologismo de democracia paralela, empregado para designar as múltiplas formas de atuação dos governos subnacionais nas relações internacionais, foi cunhado a partir da década de 1980 e tem como referências doutrinárias pioneiras as obras de Ivo Duchacek (1990 apud PRADO, 2018, p. 139) e de Panayotis Soldatos (1986 apud PAQUIN, 2004, p. 16). Outras expressões têm sido empregadas pela doutrina ${ }^{17}$, propostas em razão da funcionalidade e dos limites dessa nova perspectiva das relações internacionais, embora não tenham a acolhida predominante entre os estudiosos da matéria.

A paradiplomacia é um conceito desenvolvido especialmente no âmbito das Ciências Sociais e das Relações Internacionais, elaborado para explicar o protagonismo dos governos subnacionais na ordem internacional, no contexto do mundo globalizado, complexo e desafiador de concepções tradicionais relacionadas ao Estado-Nação. Ao estudar a trajetória da paradiplomacia, Arenas-Arias $(2018$, p. 4) explica que "o Estado-nação é visto como um ator multivocal (polifônico) que se expressa na cena internacional com mais vozes que a legitimidade do governo central".

16 Sobre o não agir ut singuli, sugere-se a leitura de Miranda (1936, p. 33).

17 Débora Prado (2018), em estudo sobre as construções conceituais da paradiplomacia, estabelece sistematização conceitual do fenômeno na doutrina estrangeira e brasileira. Assim, a autora apresenta e analisa as expressões: democracia multinível, microdiplomacia, "constituent diplomacy", diplomacia multicamadas, diplomacia subestatal, política externa federativa, diplomacia federativa (Itamaraty), cooperação internacional descentralizada, cooperação multinível. 
Apesar de compreender vários graus e perspectivas de atuação dos entes não centrais no cenário internacional, desde questões de low politics (intercâmbios culturais, cooperação técnica e turismo, por exemplo) até pretensões separatistas, a paradiplomacia coloca a questão da possibilidade de atuação de entes destituídos de soberania e de personalidade no direito internacional, como é o caso tipicamente dos Estados e Municípios nos Estados Federais.

Um dos grandes possíveis entraves à compreensão da paradiplomacia como categoria útil ao desenvolvimento das relações internacionais e à proteção dos direitos humanos e do meio ambiente parte de definições tradicionais da Teoria do Estado e do Direito Internacional, anteriores à expansão do direito internacional dos direitos humanos. Neste sentido, sobre os sujeitos de direito internacional público alude-se à personalidade internacional como faculdade de atuação direta na ordem internacional, com poderes de criação de normas de direito internacional, do exercer direitos, contrair obrigações e recorrer a mecanismos internacionais de proteção. São reconhecidos como detentores de tal status, por exemplo, os Estados Soberanos, organizações internacionais, blocos regionais e algumas nações que lutam pela soberania.

A doutrina mais recente do direito internacional, em especial do direito internacional dos direitos humanos, questiona conceitos tradicionais e os pilares da soberania estatal formulada a partir de herança hobbesiana, atribuindo personalidade internacional a empresas, a organizações não governamentais e ao próprio indivíduo, alçado ao patamar de sujeito de direito internacional.

A afirmação de que os Estados-membros não podem agir ut singuli na ordem internacional, marco divisor da Federação e da Confederação, merece ressignificação no novo contexto mundial e deve ser compreendida a partir também de limites específicos da Constituição do Estado Federal. Não é possível emprestar da doutrina uma cláusula geral definidora de uma forma de organização política territorial - que, aliás, apresenta múltiplas nuances nos diversos Estados federais - e empregá-la para engessar a dinamicidade das relações internacionais e federativas no mundo globalizado do século XXI.

A Constituição brasileira de 1988 atribui primazia ao poder central para atuar na ordem internacional, como instrumento de indissolubilidade do pacto federativo e uniformidade em alguns assuntos como relações diplomáticas em sentido estrito, celebração de tratados internacionais que 
impliquem compromissos gravosos ao patrimônio nacional (Art. 49, I c/c art. 84, VIII da CRFB/88). Também sujeitas ao crivo do Senado Federal, estão operações externas de natureza financeira dos entes federativos (art. 52, $\mathrm{V}$ da $\mathrm{CRFB} / 88$ ), com o intuito de impedir a responsabilidade da federação. Cabe ressaltar, por exemplo, as alterações trazidas pela EC n. 45/2004 sobre a federalização dos crimes contra os direitos humanos (art. 109, V- A e $\S 5^{\circ}$ da CRFB/88.) para assegurar o cumprimento de obrigações do Estado brasileiro decorrentes de tratados internacionais de direitos humanos, em substituição à atuação dos Estados-membros.

As relações internacionais no século XXI abrangem, porém, múltiplas possibilidades de atuação não resumida nas manifestações de soberania do Estado. Assim, convênios tecnológicos, cooperação cultural, turismo, educação, comércio de bens e serviços são exemplos de matérias que não apresentam em si ameaça à integridade da Federação.

Os Estados federados e Municípios, de outra perspectiva, têm atribuições predefinidas na Constituição Republicana de 1988, cujo cumprimento e responsabilidade transcendem a anuência ou atuação da União Federal. A Constituição brasileira, em seu art. 18, caput, ao versar sobre a organização político-administrativa da República Federativa do Brasil, faz referência expressa à autonomia da União, dos Estados, do Distrito Federal e dos Municípios, desenhando, em seguida, um mapa de competências legislativas e administrativas, e estabelecendo inclusive a responsabilidade solidária dos entes federativos em seu art. 23. A proteção do meio ambiente, neste sentido, é atribuição conjunta dos três níveis federativos, cuja responsabilidade é solidária e inescusável ao argumento de que os entes não centrais trilharam políticas eventualmente desastrosas sob a batuta da União Federal.

O quadro normativo constitucional brasileiro impõe a análise das espécies ou manifestações da paradiplomacia em sentido amplo para verificação de sua legitimidade constitucional no Brasil. Em razão da diversidade de mecanismos, finalidades e intensidade da atuação dos governos subnacionais no plano internacional, os estudiosos do tema apresentam critérios classificatórios, cabendo destacar a protodiplomacia e a paradiplomacia global.

Em primeiro lugar, a protodiplomacia é uma atividade de um governo subnacional contrária à diplomacia nacional, desestabilizadora, podendo inclusive configurar trabalho preparatório à secessão e manifestamente incompatível com a unidade do Estado brasileiro (PRADO, 2018).

A paradiplomacia global, diversamente, corresponde à ação dos Esta- 
dos federados que entram em contato não apenas com centros financeiros, industriais ou culturais no exterior do país, mas igualmente com as agências de países estrangeiros. ${ }^{18} \mathrm{O}$ sistema constitucional brasileiro não impõe restrição aos entes não centrais, Estados-membros e Municípios para que estes protagonizem relações internacionais, especialmente em temas como meio ambiente, cuja proteção não reconhece limites humanos como as fronteiras geográficas. O Consórcio Amazônia Legal, em tal contexto, figura-se como instrumento de cooperação federativa paradiplomático dotado de legitimidade constitucional, cuja principal funcionalidade política e jurídica reside em cumprir obrigações constitucionais com auxílio e recursos de governos estrangeiros, sem qualquer afronta à integridade nacional.

Assim, considerando a problemática de atuação dos Estados-membros para o desenvolvimento da região amazônica, observa-se que não caberá a tais entes atuar como representantes internacionais do Estado brasileiro, atividade já mencionada, a qual compete exclusivamente à União (art. 21, inciso I). Esses entes consorciados, embora formalmente destituídos de personalidade jurídica de direito internacional, podem se relacionar com outros Estados por meio de convênios.

Ao abordar o tema da inserção internacional de unidades subnacionais, Branco (2007) indica a atuação em termos de realização de Tratados Internacionais por subunidades nas antiga União das Repúblicas Socialistas Soviéticas, Alemanha Ocidental, Argentina e Suíça, constando expressamente o jus tractum das entidades infraestatais nas Constituições daqueles Estados.

$\mathrm{Na}$ Constituição Alemã de 1949, há previsão no art. $24^{19}$ da possibilidade de delegação de soberania para Estados-membros, sendo uma demonstração de que a questão da realização de Tratados Internacionais por parte daqueles pode se dar por previsão constitucional, sem que isso seja visto como uma afronta ao regime federal.

Já houve no ordenamento jurídico brasileiro a tentativa de se estabelecer a paradiplomacia, no sentido próprio da possibilidade de os Estados-membros e Municípios tornarem-se sujeitos de direito público internacional para celebrarem Tratados Internacionais, como foi o caso da PEC n. 475/2005, todavia arquivada, sob o argumento de inconstitucionalidade

18 Sobre as espécies de paradiplomacia, Ivo Duchacek (1986 apud PAQUIN, 2004, p. 16) trata de microdiplomacia regional transfronteiriça, microdiplomacia transregional, paradiplomacia global e protodiplomacia.

19 Art. 24 [Transferência de direitos de soberania - Sistema coletivo de segurança] (1) A Federação pode transferir direitos de soberania para organizações interestatais, por meio de lei. 
em relação ao art. 18 da CRFB/1988. Uma PEC que ajustasse a Federação, atendendo ao que modernamente vem ocorrendo pela ampliação de atribuições dos entes federados, pode ser realizada, desde que a essência do regime federal se mantenha, ou seja, mantenha a unidade nacional, mas com respeito à diversidade regional. $\mathrm{O}$ fenômeno da paradiplomacia já está instalado no Brasil, sem regulação apropriada, mas já reconhecido pelo próprio Ministério das Relações Exteriores, por meio da atuação da Assessoria Especial de Assuntos Federativos e Parlamentares ${ }^{20}$, visto que a referida Assessoria avalia as iniciativas paradiplomáticas dos Estados-membros e dos Municípios. Nesse sentido, a paradiplomacia deve ser constitucionalmente regulada.

\section{CONSIDERAÇÕES FINAIS}

Constata-se que se, no plano ambiental constitucional, houve considerável avanço da proteção ao Meio Ambiente a partir da Constituição brasileira de 1988, no âmbito das relações internas espaciais de poder, porém, houve baixa efetividade do princípio federativo, no sentido de exercício de poder autônomo dos entes da federação até este momento.

Quer dizer, não bastou a previsão constitucional de responsabilidade administrativa e legiferante no tocante ao direito ambiental, pois a efetividade de tais responsabilidades pode ser questionada diante da degradação e do desmatamento da Amazônia Legal brasileira, visto que tais ocorrências não aconteceram naturalmente, mas por ação humana. Assim, constar normatizado constitucionalmente não significa que a proteção ambiental será eficaz. Com isso, políticas ambientais, para além das leis, devem ser fomentadas, estabelecidas e realizadas não somente pela União.

A situação de mudança dos critérios de utilização dos recursos do Fundo Amazônia fez que o poder dos entes federados fosse revisitado e reavaliado, pois a falta de recursos afetou diretamente os Estados-membros da Amazônia Legal, os quais têm responsabilidades constitucionais com o meio ambiente. Logo, devem atuar em prol deste.

A paradiplomacia designa o caminho para o contato internacional que os entes federados podem realizar, a fim de consolidar a aquisição de recursos por doações para o desenvolvimento cultural, turístico, tecnológico, ambiental e outros que não estejam vinculados às fronteiras geográficas fictícias e até naturais.

Nesse sentido, tais entes federados da Amazônia Legal brasileira já

20 Para o tema sugere-se a leitura de Bohn e Krieger (2019, p. 1-14). 
consorciados devem agir por meio de instrumentos paradiplomáticos, a fim de atrair investimentos e doações para a preservação e o desenvolvimento sustentável da floresta amazônica, com intuito de romper o ciclo de degradação e desmatamento que vem assolando a referida floresta. Tais medidas em nada atrapalham ou obstaculizam as políticas da União e a continuidade do pacto federativo, porque não há inconstitucionalidade ou deslealdade por parte dos entes da federação em receber doações e investimentos internacionais para o desenvolvimento da Amazônia brasileira. A posição dos Estados-membros é de beneficiários de recursos financeiros e tecnológicos, dentro outros, sem gravames ao patrimônio nacional.

O exercício da paradiplomacia é a resposta ao problema da pesquisa, ou seja, o contato internacional pelos Estados-membros com agências internacionais poderá servir para atrair recursos internacionais, a fim de mitigar a degradação e o desmatamento da floresta amazônica. Além disso, pode ser um viés para políticas regionais consorciadas de desenvolvimento sustentável ambiental.

Os Estados-membros podem exercer a paradiplomacia na busca de soluções para problemas regionais e locais, sem ferir o pacto federativo ou mesmo afrontar a soberania que a União representa. O direito ambiental como direito constitucional comum é objeto de atenção e deve ser zelado por todos os entes federados.

A importância da paradiplomacia está em equilibrar as relações intergovernamentais entre os entes federados, porque divide as responsabilidades entre a União e os Estados-membros pela manutenção da floresta amazônica, descentralizando-se tais responsabilidades. Não sendo constatados conflitos e nem competitividade entre a União e os Estado-membros pelo exercício de contatos paradiplomáticos, pode-se apenas observar que os Estados-membros têm relevância para a manutenção e o desenvolvimento da região amazônica.

A realização de Tratados Internacionais tendo como sujeitos os Estados-membros depende de alteração da Constituição brasileira de 1988, de modo a compatibilizar aos tempos atuais as dimensões administrativas, políticas e regionais a que o Brasil está imerso.

\section{REFERÊNCIAS}


ABDENUR, A. E.; MUGGAH, R. Amazônia e soberania nacional. Le Monde Diplomatique Brasil, 22 set. 2019. Disponível em: https://diplomatique.org.br/amazonia-e-soberania-nacional/. Acesso em: 29 nov. 2019.

AFFONSO, R. B. Á. Descentralização e reforma do Estado: a Federação brasileira na encruzilhada. Economia e Sociedade, Campinas, n. 14, p. 127-152, jun. 2000. Disponível em: http://www.eco.unicamp.br/images/ arquivos/artigos/506/05-RuiAffonso.pdf. Acesso em: 17 ago. 2019.

ALEMANHA. Lei Fundamental da República Federal da Alemanha, 1949. Disponível em: https://www.btg-bestellservice.de/pdf/80208000. pdf. Acesso em: 14 out. 2020.

AMAZONAS. Lei n. 4.530, de 26 de dezembro de 2017. Ratifica o Protocolo de Intenções firmado entre os Estados do Amazonas, Acre, Amapá, Maranhão, Mato Grosso, Pará, Rondônia, Roraima e Tocantins, com vistas ao desenvolvimento da Amazônia Legal, de maneira harmônica e sustentável, e dá outras providências. Diário Oficial do Estado do Amazonas, Manaus, 26 dez. 2017.

ARENAS-ARIAS, G. J. Paradiplomacia: definiciones y trayectorias. Papel Político, v. 23, n. 2, p. 1-19, 2018. Disponível em: https://doi.org/10.11144/ Javeriana.papo23-2.pddt. Acesso em: 5 jan. 2020.

BOCAIÚVA, Q. et al. Manifesto Republicano de 1870. In: BRASILIENSE, A. Os programas dos partidos e o $2^{\circ}$ Império. [s.1.]: [s.n.], 1878. p. 59-88. Disponível em: https://edisciplinas.usp. br/pluginfile.php/4360902/ mod_resource/content $/ 2 /$ manifesto\%20republicano\%201870.pdf. Acesso em: 14 nov. 2019.

BOHN, R. S.; KRIEGER, V. C. Paradiplomacia: um estudo das Politicas Externas do Estado de Santa Catarina. Disponível em: http://app.catolicasc.org.br/ojs/index.php/NovosSaberes/article/view/156. Acesso em: 14 out. 2020 .

BORGES, A. Governo quer usar Fundo Amazônia para indenizar desapropriações. Estadão. 25 de maio de 2019. Disponível em: https://sustentabilidade.estadao.com.br/noticias/geral,governo-quer-usar-fundo-amazonia-para-indenizar-desapropriacoes,70002842939. Acesso em: 29 nov. 2019.

BRANCO, Á. C. C. A paradiplomacia como forma de inserção internacional de unidades subnacionais. PRISMAS: Dir., Pol.Pub. e Mundial., 
Brasília, v.4, n, 1, p 48-67, jan/jul. 2007. Disponível em: https://www.publicacoesacademicas.uniceub.br/prisma/article/view/216. Acesso em: 14 out. 2020 .

BRASIL. Banco Nacional do Desenvolvimento. Fundo Amazônia 10 anos: relatório de atividades 2018. Brasília, DF: BNDES, 2019a. Disponível em: http://www.fundoamazonia.gov.br/export/sites/default/pt/.galleries/documentos/rafa/RAFA_2018_port.pdf. Acesso em: 17 ago. 2019.

BRASIL. Assembleia Legislativa do Estado do Pará. Banco de Leis. Disponível em: https://www.alepa.pa.gov.br/bancodeleis.asp. Acesso em: 14 nov. 2019.

BRASIL. Ministério da Relações Exteriores. Plano de Dados Abertos do MRE 2020-2021: consulta pública. Brasília, DF: MRE, 2019b. Disponível em: http://www.itamaraty.gov.br/pt-BR/artigos-de-politica-externa/ 20944-alemanha-confirma-recursos-para-o-fundo-amazonia-falta-a-noruega-uol-3-de-outubro-de-2019. Acesso em: 25 nov. 2019.

BRASIL. [Constituição (1988)]. Constituição da República Federativa do Brasil. Brasília, DF: Presidência da República, 1988. Disponível em: http://www.planalto.gov.br/ccivil_03/constituicao/constituicao.htm. Acesso em: 25 nov. 2020.

BRASIL. Presidência da República. Casa Civil. Subchefia para Assuntos Jurídicos. Lei $n$. 6.938, de 31 de agosto de 1981. Dispõe sobre a Política Nacional do Meio Ambiente, seus fins e mecanismos de formulação e aplicação, e dá outras providências. Brasília, DF: Presidência da República, 1981. Disponível em: http://www.planalto.gov.br/ccivil_03/leis/16938. htm. Acesso em: 25 nov. 2020.

BRASIL. Presidência da República. Casa Civil. Subchefia para Assuntos Jurídicos. Lei $n$. 9.605, de 12 de fevereiro de 1998. Dispõe sobre as sanções penais e administrativas derivadas de condutas e atividades lesivas ao meio ambiente, e dá outras providências. Brasília, DF: Presidência da República, 1998a. Disponível em: http://www.planalto.gov.br/ccivil_03/leis/ 19605.htm. Acesso em: 25 nov. 2020.

BRASIL. Câmara dos Deputados. Emenda Constitucional n. 19, de 1998. Modifica o regime e dispõe sobre princípio e normas da Administração Pública, Servidores e Agentes políticos, controle de despesas e finanças públicas e custeio de atividades a cargo do Distrito Federal, e dá outras 
providências. Brasília, DF: Câmara dos Deputados, 1998b. Disponível em: https://www2.camara.leg.br/legin/fed/emecon/1998/emendaconstitucional-19-4-junho-1998-372816-exposicaodemotivos-148914-pl.html. Acessado em: 25 nov. 2020.

BRASIL. Presidência da República. Secretaria-Geral. Subchefia para Assuntos Jurídicos. Decreto n. 9.579, de 11 de abril de 2019. Extingue e estabelece diretrizes, regras e limitações para colegiados da administração pública federal. Brasília, DF: Presidência da República, 2019. Disponível em: http://www.planalto.gov.br/ccivil_03/_ato2019-2022/2019/decreto/ D9759.htm. Acesso em: 25 nov. 2020.

BRASIL. Presidência da República. Secretaria-Geral. Subchefia para Assuntos Jurídicos. Decreto n. 6.527, de 1 de agosto de 2008. Dispõe sobre o estabelecimento do Fundo Amazônia pelo Banco Nacional de Desenvolvimento Econômico e Social - BNDES. Brasília, DF: Presidência da República, 2008. Disponível em: http:/www.planalto.gov.br/ccivil_03/_ ato2007-2010/2008/decreto/d6527.htm. Acesso em: 25 nov. 2020.

BRASIL. Presidência da República. Casa Civil. Subchefia para Assuntos Jurídicos. Lei n. 11.107, de 6 de abril de 2005. Dispõe sobre normas gerais de contratação de consórcios públicos e dá outras providências. Brasília, DF: Presidência da República, 2005a. Disponível em: http://www.planalto. gov.br/ccivil_03/_ato2004-2006/2005/lei/111107.htm. Acesso em: 7 dez. 2019.

BRASIL. Câmara dos Deputados. Projeto de Emenda Constitucional $n$. 475/2005. Acrescenta parágrafo ao art. 23 da Constituição Federal para permitir que Estados, Distrito Federal e Municípios possam promover atos e celebrar acordos ou convênios com entes subnacionais estrangeiros. Brasília, DF: Câmara dos Deputados, 2005b. Disponível em: https://www.camara.leg.br/propostas-legislativas/305376. Acesso em: 14 out. 2020.

BRASIL. Instituto Nacional de Pesquisas Espaciais. Taxa de desmatamento - Amazônia Legal - Estados. TerraBrasilis. Disponível em: http://terrabrasilis.dpi.inpe.br/app/dashboard/deforestation/biomes/legal_amazon/ rates. Acesso em: 17 ago. 2019.

BRASIL. Presidência da República. Casa Civil. Subchefia para Assuntos Jurídicos. Decreto n. 7.030, de 14 de dezembro de 2009. Promulga a Convenção de Viena sobre o Direito dos Tratados, concluída em 23 de maio de 
1969, com reserva aos Artigos 25 e 66. Brasília, DF: Presidência da República, 2009. Disponível em: http://www.planalto.gov.br/ccivil03/ato20072010/2009/decreto/d7030.htm. Acesso em: 14 out. 2009.

BRASIL. Gráficos: desmatamento da Amazônia e do Cerrado em 2019 e mais 27 novos gráficos da sociedade civil! Educa Clima - Ministério do Meio Ambiente, 7 jan. 2020. Disponível em: http://educaclima.mma. gov.br/graficos-desmatamento-da-amazonia-e-do-cerrado-em-2019-e-mais-27-novos-graficos-da-sociedade-civil/. Acesso em: 14 out. 2020.

BRESSER-PEREIRA, L. C. Construindo o Estado republicano: democracia e reforma da gestão pública. Rio de Janeiro: FGV, 2009.

GARCIA-PELAYO, M. Derecho Constitucional Comparado. Madrid: Alianza, 1984.

HAMILTON, A.; MADISON, J.; JAY, J. O federalista. 2. ed. São Paulo: Russel, 2005.

IMAZON. Desmatamento aumenta 212\% em outubro deste ano, aponta Imazon. Belém: Imazon, 2019. Disponível em: https://imazon.org.br/imprensa/desmatamento-na-amazonia-aumenta-212-em-outubro-deste-ano-aponta-imazon/. Acesso em: 3 dez. 2019.

LEONCY, L. F. Apreciação do RDC pelo Supremo deverá considerar a lealdade federativa. Consultor Jurídico, 15 nov. 2014. Disponível em: https://www.conjur.com.br/2014-nov-15/observatorio-constitucional-supremo-devera-considerar-lealdade-federativa-apreciar-rdc?pagina=2. Acesso em: 7 dez. 2019.

MACHADO, J. A.; ANDRADE, M. L. C. Cooperação Intergovernamental, consórcios públicos e sistemas de distribuição de custos e benefícios. Rev. Adm. Pública, Rio de Janeiro, v. 48, n. 3, p. 695-720, maio/jun. 2014. Disponível em: http://www.scielo.br/scielo.php?script=sci_arttext\&pi$\mathrm{d}=$ S0034- 76122014000300008. Acesso em: 10 ago. 2019.

MARCOVITCH, J.; PINSKY, V. C. Amazon Fund: financing deforestation avoidance. R. Adm., São Paulo, v. 49, n. 2, p. 280-290, abr./jun. 2014. Disponível em: http://www.scielo.br/pdf/rausp/v49n2/06.pdf. Acesso em: 25 nov. 2019.

MARCONI, M. A.; LAKATOS, E. M. Fundamentos de metodologia científica. 5. ed. São Paulo: Atlas, 2003. 
MIRANDA, P. Comentários à Constituição da República dos Estados Unidos do Brasil. Tomo I. Rio de Janeiro: Guanabara, 1936.

PAQUIN, S. Paradiplomatie et relations internationals. Theorie des strategies internationals des regions face à la mondialisation. Bruxelles: Presses Interuniversitaires Europeennes, 2004.

PASSARINHO, N.; SENRA, R. Oferta do Canadá, Reino Unido e G7 não chegam a valor perdido com Fundo Amazônia. BBC News Brasil, 28 ago. 2019. Disponível em: https://www.bbc.com/portuguese/brasil-49450567. Acesso em: 10 set. 2019.

PARÁ. Diário Oficial do Estado do Pará. Ano CXVII da IOE $128^{\circ}$ da República n. 33.513. p. 6-18. Disponível em: http://www.ioepa.com.br/ portal/. Acesso em: 7 de dez. 2019.

PARÁ. Lei Ordinária n. 8.573, de 6 de dezembro de 2017. Ratifica o Protocolo de Intenções firmado entre os Estados do Acre, do Amapá, do Amazonas, do Maranhão, do Mato Grosso, do Pará, de Rondônia, de Roraima e do Tocantins, visando à constituição de consórcio interestadual, que tem por objeto o desenvolvimento econômico e social da Amazônia Legal. Belém: Governo do Estado do Pará, 2017. Disponível em: https://www.sistemas. pa.gov.br/sisleis/legislacao/3744. Acesso em: 25 nov. 2020.

PRADO, D. F. M. A atuação internacional dos governos subnacionais: construções, limites e contribuições para o caso brasileiro. Rev. Carta Inter., Belo Horizonte, v. 13, n. 3, p. 137-168, 2018.

SARLET, I. W.; MARINONI; L. G.; MITIDIERO, D. Curso de Direito Constitucional. São Paulo: Saraiva, 2015.

SANTOS, P. Quem deve pagar para conservar as floretas? Cienc. Cult., São Paulo, v. 70, n. 1, p. 23-24, jan./mar. 2018. Disponível

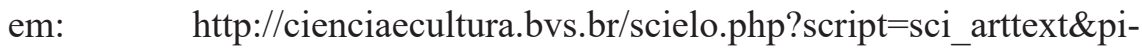
$\mathrm{d}=$ S0009-67252018000100008. Acesso em: 20 nov. 2019.

SENRA, R. Meio ambiente: Alemanha confirma bloqueio de R\$ 156 milhões e põe em xeque acordo Mercosul-EU. BBC News Brasil, 12 ago. 2019. Disponível em: https://www.bbc.com/portuguese/brasil-49325337. Acesso em: 10 set. 2019.

SILVA, J. A. Curso de Direito Constitucional Positivo. 32. ed. São Paulo: Malheiros, 2009. 
SILVA, L. B.; CARVALHO, L. F. Federalismo e Centralização no Brasil: contrastes na construção da federação brasileira. Revista de Direito da Cidade, Rio de Janeiro, v. 10, n. 3, p. 1483-1503, 2018. Disponível em: https://www.e-publicacoes.uerj.br/index.php/rdc/article/view/32661. Acesso em: 12 set. 2019.

TAVARES, A. R. Curso de Direito Constitucional. São Paulo: Saraiva, 2013.

WOLFRUM, R. HESTERMEYER, H.; VÖNEKY, S. The Reception of Internacional Law in the Germain legal order: an introduction. In: WET, E.; HESTERMEYER, H.; WOLFRUM, R. The implementation of International Law in Germany and South Africa. Pretoria: Pretoria University Law Press, 2015. p. 2-22. Disponível em: https://www.researchgate.net/ publication/306400927_The_reception_of_international_law_in_the German_legal_order_An_introduction. Acesso em: 14 out. 2020.

WRIGHT, D. S. Intergovernmental relations: an analytical overview. The Annals of the American Academy of Political and Social Science, v. 416, p. 1-16, 1974.

ZAGO, M. A. S. Federalismo no Brasil e na Alemanha: estudo comparativo de repartição de competências legislativas e de execução. Tese (Doutorado em Direito do Estado) - Faculdade de Direito, Universidade de São Pulo, São Paulo, 2016.

Artigo recebido em: 07/02/2020. Artigo aceito em: 18/12/2020.

\section{Como citar este artigo (ABNT):}

TEIXEIRA, E. M. S. F.; CICHOVSKI, P. L. B. A paradiplomacia e a gestão da Amazônia no federalismo brasileiro. Veredas do Direito, Belo Horizonte, v. 17, n. 39, p. 309-337, maio/ago. 2020. Disponível em: http://www. domhelder.edu.br/revista/index.php/veredas/article/view/1771. Acesso em: dia mês. ano. 